\title{
COST STUDY OF COASTAL PROTECTION
}

\author{
Marc Igigabel $^{1}$ and Marissa Yates ${ }^{2}$
}

A better definition of the long term protection strategies against littoral hazards requires evaluating investment, management, and maintenance costs of various interventions on levees and other civil engineering structures, as well as on beaches and dunes. The cost study of coastal protections (Cerema 2018) aims at providing the assessment of the project global cost. Based on the study of a large number of projects completed in France, estimations were produced to enhance the reliability of these calculations at the scale of a site in the littoral zone or of an individual natural or artificial structure. For each structure type, the obtained results are essentially linear, surface, volume or mass costs (initial costs or annual average costs), as well as lifetime and intervention frequency. To obtain this information, the analysis mainly consisted of:

- the creation of a typology which crosses « structure type » and « intervention type » which allows establishing homogeneous groups of characteristic operations;

- the identification, for every group, of physical parameters influencing the associated costs, which allows the user of the manual to evaluate better the difference between the observed high and low values.

This paper presents the context of the study, its methodological process, the progress of the investigations and the analyses, the obtained results, and finally the generic lessons learned.

Keywords: cost, protection, defense, sea, flood, erosion, levee, dune, beach

\section{INTRODUCTION}

The traditional techniques of «sea defenses » are frequently used on the French coast, showing mixed results of their efficiency. Moreover, the use of these techniques is often controversial because of the artificialisation of the landscapes and the impacts on the environment. This has led to an evolution of public policies and to the emergence of new protection strategies.

Coastal features vary significantly (beaches and dunes, polders and swamps, estuaries and deltas) but all have in common a dynamic mobility that causes their evolution in time. This instability strongly questions the sustainability of hard structures. In spite of the impression of robustness that materials such as armourstone, concrete and steel provide, these structures are fragile when subjected to storms. New evidence of this fragility was shown during the recent storms in France. On February 28th, 2010, the Xynthia storm highlighted the necessity of improving levee systems to protect against marine floods, and a series of storms in the winter 2013-2014 was a reminder of the sensitivity of our coasts to erosion.

Natural features (consisting of mud, sand or pebbles), as well as certain types of vegetation, are often the best way to dissipate wave energy. The implementation of traditional protection structures modifies the complex sediment transport balances existing on coasts. In particular, foreshore erosion can be caused by:

- the reflection of waves on concrete or steel seawalls;

- the interruption of the sediment transport when groynes are placed along beach profiles.

In spite of high construction, maintenance and repair costs, traditional works generate strong impacts on the environment and on landscapes, and may offer only limited protection against littoral hazards.

Based on these limitations, alternative solutions have been developed that disrupt less the complex dynamics existing on the coast. If these solutions are already implemented at numerous sites, protection strategies against littoral hazards must still be questioned at an even greater number of sites, and in most cases, redefined. Yet, long-term project funding often represents the main barrier to this evolution. It was thus advisable to produce a methodological handbook assembling useful information and pertinent recommendations to compare in the long term the protection scenarios of projects employing these techniques. In particular, the goal is to calculate the global cost, summing the investment, management, and maintenance costs. This is the scope of the handbook produced by the Cerema (2018) on the basis of the observation of a wide variety of projects completed during the last fifteen years in France. The present article presents this study, focusing more particularly on information relevant not only in France, but on an international scale. The flowchart in Figure 1 gives an overview of the contents of the study and is a recommended outline to follow for similar studies.

\footnotetext{
Cerema, Technopôle Brest Iroise, 155 rue pierre Bouguer, BP5, 29280 Plouzané, France

2 Saint-Venant Hydraulics Laboratory \& Cerema, 6 quai Watier, BP 49, 78401 Chatou, France
} 


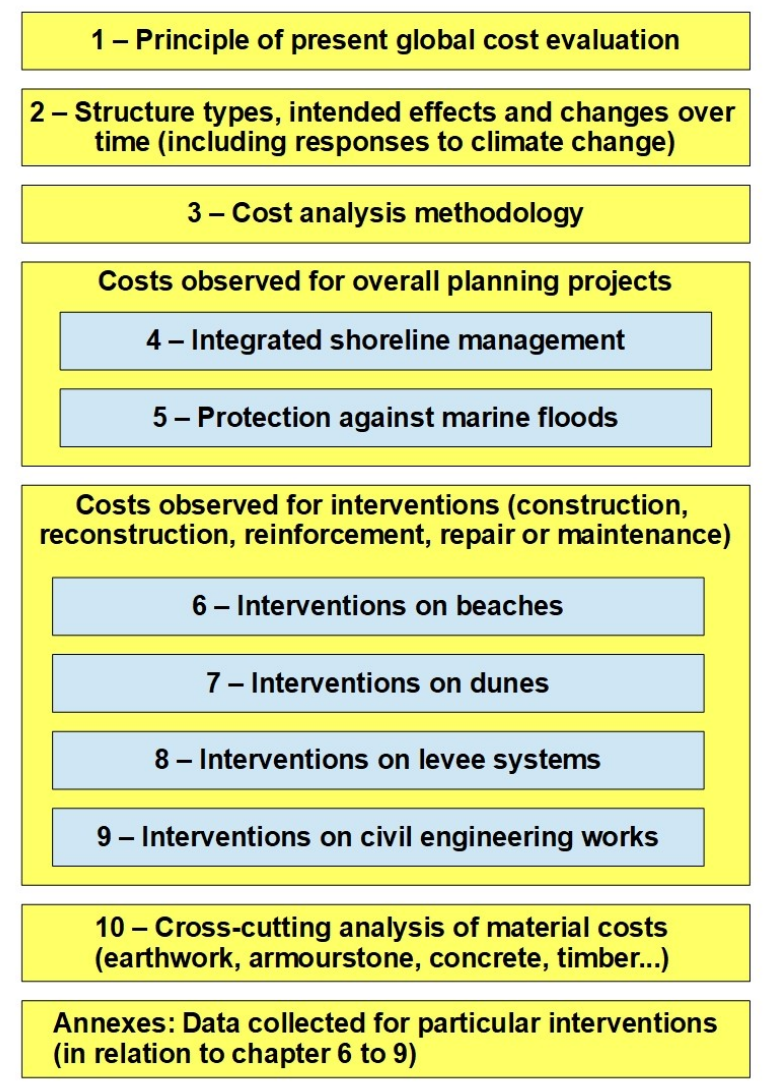

Figure 1. Flowchart of the study

\section{CONTEXT OF THE STUDY}

The study (Cerema 2018) is based on the observation of past projects. To appreciate the possibility to conduct this type of study, it is necessary:

- first, to have a sufficient understanding of the protection strategies that these projects are fulfilling;

- $\quad$ secondly, to make sure that the geographical perimeter of investigations and the nature of the concerned coast, in connection with the historic context of the studied period, guarantees favourable conditions to obtain sufficient data for the establishment of reliable estimations of unit costs and other researched data.

\section{Protection strategies against coastal hazards}

For certain sites, the main problem is the management of beaches and dunes in connection with the sediment transport. Other sites are more concerned by the protection against coastal flooding. To deal with these two problems, projects will inevitably refer to:

- the shoreline position, which marks the limit between land and sea. This limit moves depending on erosion and accretion processes, under the influence of hydro-sedimentary and aerial processes, as well as changes in sea level. Generally, the main objective is to avoid that erosion causes shoreward movement of the shoreline position, ultimately threatening coastal infrastructure and populations;

- levee systems, whose function is to protect against marine flooding. These systems consist of levees and hydraulic structures assuring the flow regulation between the various sections of the system and between the land and the sea.

The position of levee system structures does not coincide a priori with the shoreline: setback levees, canals, or retaining basins are positioned land-side. Nevertheless, a variety of means to manage the shoreline position and to protect against marine flooding are common: in many cases, the preservation of the sedimentary stock, as well as structures positioned on the foreshore to absorb wave energy, are deemed necessary to reach these two objectives. 


\section{Historical background and geographic scope of the study}

The study (Cerema 2018) was conducted in France. The coastline of metropolitan France extends nearly $6200 \mathrm{~km}$, excluding estuaries and ports (MEEM 2015), and every coastal type is represented (IGN 2007):

- $\quad 2200 \mathrm{~km}$ of sandy coast (35\%);

- $1500 \mathrm{~km}$ of marshes and tidal reservoirs (24\%);

- $2500 \mathrm{~km}$ of rocky coasts (41\% with $13 \%$ cliffs).

The evolution of public policies during the studied period 2002-2017 led to the implementation in France of a wide variety of protection strategies against coastal hazards. The most pronounced examples are the restorations of lidos (strips of land made of sand that close lagoons) in the Mediterranean Sea and the large-scale works on the Atlantic coast conducted after the Xynthia storm. These projects are defined in action plans that can be classified in three categories:

1. projects designed to protect against littoral hazards taking into account the hydro-sedimentary functioning of sites, but constrained by the strong public policy issues (which explains that the use of civil engineering structures is still frequent);

2. restoration of the coastal zone intended to return to a more natural functioning of the environment ;

3. management and maintenance on sites at which the natural character was widely protected (beaches and dunes, coastal marshes), or on the contrary, at sites marked by a strong human activity.

In the first two categories, all in all 173 projects were taken into account in the study (Cerema 2018). The location of these projects is shown in Figure 2, but the figure does not include the maintenance interventions on natural sites of the third category (especially dunes), which were also considered on the basis of the annual activity reports.

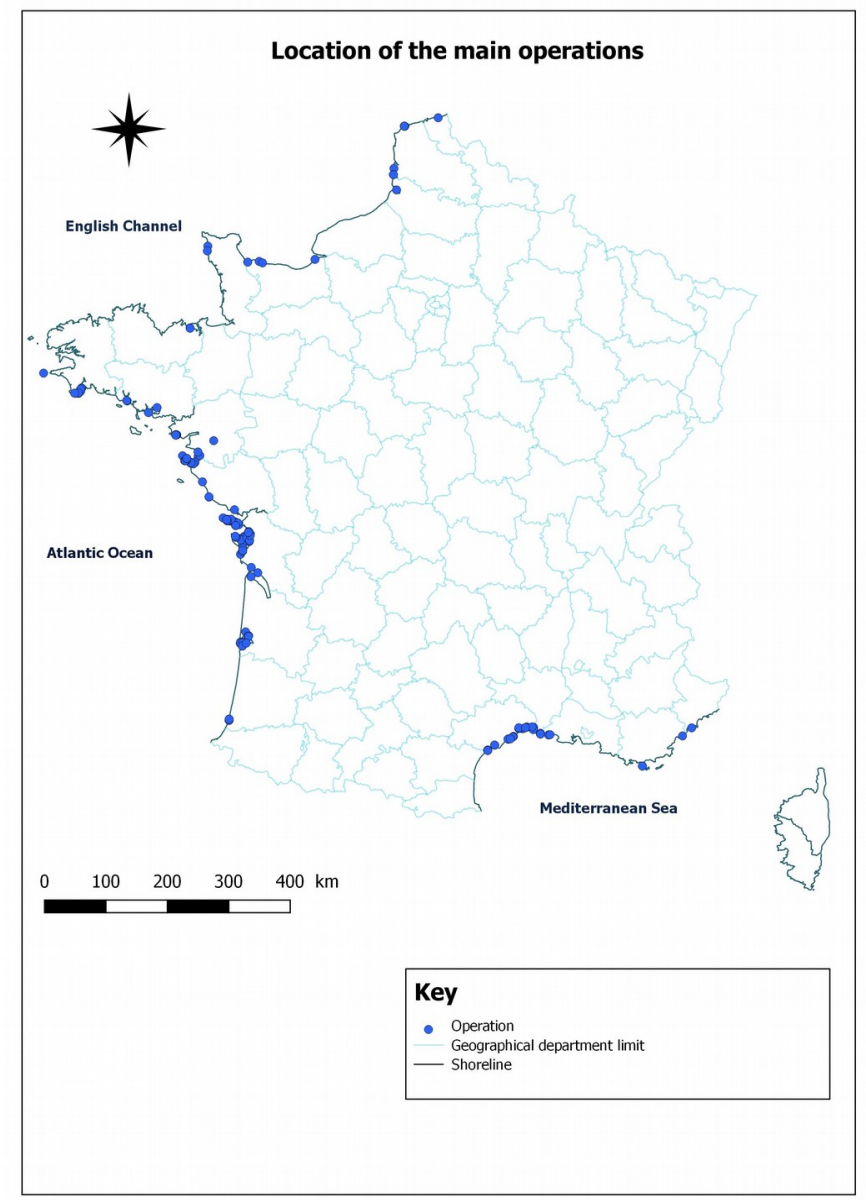

Figure 2. Location of main studied projects 
To give a sense of scale of expenditures dedicated to these objectives in France:

- over the period 2007-2013, on the West part of the Mediterranean coast (Occitanie), the investment over 7 years for the rehabilitation of the coastal zone represents $120 \mathrm{M} €$ (value updated in 2014);

- $\quad$ over the period 2011-2016, on sectors affected by the storm Xynthia (center of the Atlantic facade), expenditures over 6 years amounted to $300 \mathrm{M} €$ (CGEDD 2013).

\section{CALCULATION OF THE GLOBAL COST AND COMPARISON OF PROTECTION SCENARIOS}

To define and estimate the cost of the projects protecting against littoral hazards requires having a relevant calculation method of the global cost. This method applies normally within the framework of the comparison of scenarios ending in the adoption of a strategy. Each scenario can concern several natural features or structures. Thus, the principle is, for each scenario, to calculate the global cost of each component. The global cost of a scenario is thus the sum of the global costs of its components.

\section{Comparison of protection scenarios}

Every project should be designed considering the geographical scope and time scales adapted to the stakes that must be protected. The approach consists mainly of:

- defining exactly the objectives of protection against littoral hazards;

- defining scenarios of protection and identifying for each of them the outline of the project and the planned techniques;

- $\quad$ estimating the investment, maintenance, and management costs (global cost) of the project for each of the scenarios.

On the basis of these elements, detailed below, and by taking into account the level of funding, it is possible to determine the most adapted strategy to reach the objectives.

\section{Definition of objectives}

It is essential:

- $\quad$ to identify the stakes that must be protected;

- to know the reference events (storm, flood) against which protection is necessary;

- to determine a lifetime of the project.

On this last point, it is important to underline that estimations must be made in a temporal perspective which is intrinsic to each project and should be explicitly defined:

- if the project aims only at maintaining a level of protection, the estimations can, for example, be established over a 30-year horizon (considering that it is about the life expectancy of the structures);

- if the issue of the protection objectives is raised and a comparison with the value of the stakes must be established, it can then be preferable to consider a duration of 100 years, while taking into account climate change effects.

\section{Definition and study of protection scenarios}

The outline of the project must be well defined by integrating the intellectual services, possible land acquisitions, and, especially, associated elements (corresponding to a function other than the protection against littoral hazards: public road networks, access to the foreshore, buildings...) that are created or impacted by the works. Costs of interventions on these associated elements can be equivalent or even superior to those of the hydraulic works. In particular, these associated elements can have a significant impact on long-term costs.

Whenever possible, the comparison should take into account all of this information, both for the calculation of initial costs and for the calculation of management and maintenance costs. However, in the rest of this paper, the subject will be restricted to the structures and natural features that have a protection function.

Before any economic comparison, it is essential to evaluate the long-term behavior of these elements. The most important part of their global cost can, most of the time, also be attributed to their management and maintenance. 
Consequently, it is recommended to study two types of measures:

- measures requiring small annual interventions (beaches, dunes equipped with fences made of wooden slats or covered with oyat plants, levees covered with grass, groynes made of timber piles);

- measures requiring irregular, but more extensive, repair and maintenance interventions (reinforced concrete structures, sheet piling or armourstone).

Measures of the first type present numerous advantages:

- better control of the level of protection due to regular monitoring of the structure and the site, and the possibility to add materials, if need be;

- better environmental balance by the use of natural materials, generally present near the project site;

- better control of the costs, which are more regularly spread out in time.

Once the qualitative study is completed, the comparison between solutions can be achieved by a quantitative approach evaluating the global cost.

\section{Method of calculation of the present global cost}

The present global cost of a structure is defined as the sum of the initial investment cost and the management and maintenance costs during the life of the project. Within the framework of cost-benefit analyses, its calculation is based on costs without the value-added tax (taxes are transfers, and not net losses or gains). In theory, the global cost of a project is equal to the difference between:

- the global cost of the reference scenario excluding the implementation of the project. The initial cost of investment is then zero and the management and maintenance expenditures follow their « natural trend»;

- the global cost resulting from the project, namely the sum of the initial investment cost and the management and maintenance costs.

For each term of this difference, the global cost for an n-year time horizon is:

$$
C_{\text {Global }}=C_{0}+\sum_{i=0}^{n} \frac{C_{i}}{\left(1+r_{i}\right)^{i}}
$$

With:

$\mathrm{C}_{0}$ the initial investment cost without value-added tax ;

$\mathrm{C}_{\mathrm{i}}$ the cost of the management and maintenance expenditures occurring in year $\mathrm{i}$

$\mathrm{r}_{\mathrm{i}}$ the discount rate in the year i. France Stratégie (2013) recommends a 2,5\% discount rate until 2070 and then a $1,5 \%$ discount rate within the framework of risk management investments.

Note that the calculation of cumulative management and maintenance expenditures is very sensitive to the discount rates. The calculation can be completed by following the three stages described in Figure 3.

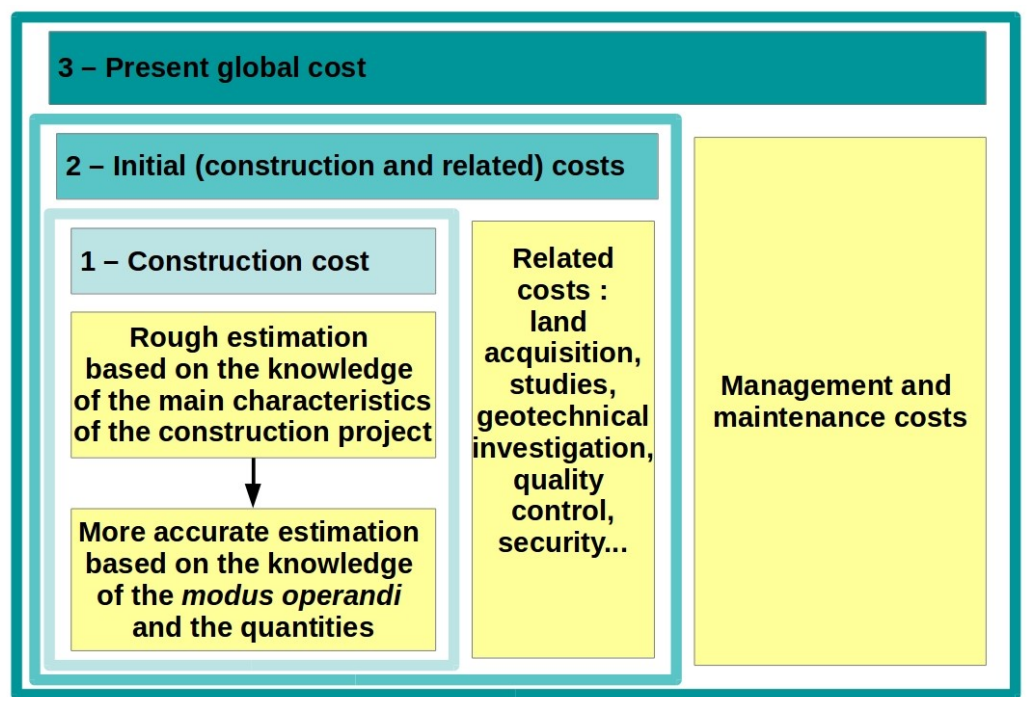

Figure 3. Calculation method of the present global cost 


\section{STUDY PROTOCOL}

The handbook (Cerema 2018) contains analyses at two different spatial scales:

- the analysis on the scale of the coastal sites. This analysis gives a global vision of the composition of large investment programs and of the spending associated with the various types of projects. At this scale, it was not possible at the time of the study to collect real management and maintenance costs data and to derive annual mean values. This analysis remains however very interesting to develop knowledge on the composition of multiple coastal projects and on the corresponding initial costs. The global project cost is calculated by considering each natural feature and structure (considered in detail in the following section), and this fortunately does not reduce the operational reach of the handbook;

- the analysis at the scale of natural features and structures, extended by additional analyses at the scale of structure components or individual devices installed on natural features. Fundamentally, this part aims to classify the recorded operations and, for each operation type, to identify the information (mainly unit costs, but also life expectancy and intervention frequency), which will be necessary to calculate the global costs of protection scenarios, to compare these global costs, and to aide in decision-making.

To appreciate the extent of the estimations, this section provides insight on the study protocol which allowed obtaining the necessary data at the two spatial scales.

\section{Analysis frames at the scale of coastal sites}

To complete the first phase of observation and analysis, two strategy types were studied, which apply, separately or jointly, to coastal zones:

- $\quad$ strategies of shoreline management;

- $\quad$ strategies of protection against marine flooding.

The interventions relative to these two strategies correspond to two sets that overlap partially. Nevertheless, in coherence with the current organization of the public policies, a first estimate of linear investment costs can be acquired by this approach.

\section{Analysis of shoreline management projects}

The shoreline management projects benefited from an adapted analysis frame. In investment programs, the following expenditure types were listed:

- $\quad$ studies in preparatory and operational phases (environmental assessment, planning, project management, topography, safety, and protection of the health);

- land acquisitions;

- works on the various types on natural and artificial structures (distinguishing beaches, dunes, and civil engineering structures);

- $\quad$ road works, service connections, and buildings (for projects including a land component).

This analysis provided a better knowledge of the percentage represented by each of these expenditures in investment programs.

\section{Analysis of the operations of protection against marine flooding}

As well as for shoreline management projects, the projects of protection against marine flooding benefited from an adapted analysis frame. Besides intellectual services and land acquisitions, the following expenditure types were listed:

- levee construction, reconstruction, reinforcement and increase;

- $\quad$ works on seawalls and groynes, beach and dune nourishment;

- $\quad$ works on setback levees;

- $\quad$ interventions on hydraulic works (tidal gate and drying devices).

The case comparison highlights a highly variable orientation of expenditures depending on site configurations and strategies. 
Analysis at the scale of natural features and civil engineering works

To extend the analysis at the scale of natural features and civil engineering works, particular attention should be paid to structure life cycles because these cycles imply different expenditure rhythms that strongly influence the calculation of present global costs.

The handbook therefore integrates the costs of diverse intervention types, which can be completed independently or jointly within the context of a larger-scale project including:

- beach nourishment, as well as hydraulic bypass systems and beach drains favoring sedimentation ;

- dune creation, rehabilitation, or maintenance ;

- levee construction, reinforcement, and maintenance ;

- civil engineering construction, reinforcement, and maintenance (seawalls, walls and supporting structures, groynes, breakwaters, abutments).

This analysis thus required crossing the typology of the natural features and civil engineering works (beaches, dunes, levees and other structures) and the typology of the interventions (construction, reconstruction, rehabilitation, reinforcement or maintenance). Estimations obtained in this part result from the analysis of construction and intellectual service contracts, and of operating and maintenance budgets.

The outcome values are mainly:

- linear costs (values estimated for the whole project or for separated structures based on investment expenditures);

- annual average costs (values estimated especially for levees, dunes and some beach nourishment interventions, on the basis of operating and maintenance budgets) ;

- linear, surface, volume or mass costs (values estimated for different techniques based on the total cost and the prices observed on particular interventions).

In this last case, the cost study of particular interventions, based on construction contracts, requires cautious interpretation regarding protocol and countable conventions to develop reliable estimations.

\section{Desired values on particular interventions}

Whatever the intervention type, this analysis aims at determining:

- the total cost. Based on this cost and on the length of the structure, a linear cost is determined;

- the cost of different techniques by aggregating relative prices.

In the second case, appropriate unit costs for considered techniques are wanted: cost per cubic meter of the sand, cost per ton for armourstone, cost per cubic meter of concrete, etc. Where necessary, a cost per linear meter or per square meter can be determined, in particular in the case of revetments or screens (for example for seawalls or floodwalls projects).

\section{Countable conventions on unit costs associated to techniques}

Unit costs integrate all the costs that are intrinsic to the technique, which implies certain countable conventions. For example:

- «For sheetpile, the cost takes into account the following actions: to supply, to position, to beat and to cut $»$;

- «For the concrete, the coffering, supply and implementation of the concrete are taken into account. In particular, for reinforced concrete, the supply, shaping of the steel, and wedging in the coffering will be added ».

For these two techniques, the determination of quantities taken into account is relatively obvious because most of the time the construction uses exclusively imported materials. But for intervention types involving the re-use of materials in the reconstruction or rehabilitation operations, calculation rules must be refined.

For example, two special cases are:

- $\quad$ armourstone: the cost depended initially on the quantity of imported materials, but finally it was decided that the quantity of materials integrated into the structure should instead be taken into account;

- $\quad$ earthwork: the cost depended more on the excavation and filling costs than on the quantity of the materials in the structure, and it was considered that the amount of earth movement should be taken into account. 


\section{OUTCOMES OBTAINED}

In coherence with the progress of the study, the results obtained at the spatial scales of the site and the structure (natural feature or civil engineering work) are presented, provided that at the second scale, the analysis was completed on the cost of the various techniques.

To the extent possible, the study presents the observed costs with three values: low, average and high. In certain cases, cost ranges are large, and the factors determining the variations are studied. The knowledge of the conditions of project completion allows refining the assessment in this manner.

In the general case, the composition of the structures and its dimensions can be mentioned to explain the linear costs variations. However, it is naturally desirable to enrich the analyses with other considerations. Thus, the identification of the physical parameters influencing the costs must be led with a certain rigor to avoid biases in the analysis.

For example, the exposure of the coast to waves will influence the dimensions and the composition of structures (in particular for the protection of slopes by armourstone or other covers resistant to hydraulic actions) and thus their costs. On the other hand, it is not certain that the tidal range has, in the general case, a significant effect on the project cost:

- the implantation and the dimensions of the structures are defined with regard to the level reached by the maximum tide and not with regard to the tidal range;

- $\quad$ except in the case of seas with a small tidal range (for example the Mediterranean Sea) where structures can be subject to permanent hydraulic actions for several days (and not a few hours), the composition of the structures does not vary substantially in function of the tidal range height.

Although it is not possible in this paper to detail all the results obtained for every intervention type, significant results are presented concerning:

- the high and low estimations of unit costs;

- the identification of the physical parameters influencing the costs.

Some additional information is also provided relative to project life expectancy and maintenance frequency.

\section{Results obtained on the scale of sites}

At the scale of a coastal site, two determining parameters appeared during the analysis of past projects:

- the first one, situated on the sea side, was already evoked in the general case: wave exposure;

- the second one is situated on the land side: the stakes that must be protected, which represent a determining parameter for expenditures recorded at the level of global action plans.

If the value of the stakes that must be protected is high enough, an additional financial effort may be accepted to increase the dimensions of a structure and to strengthen them with facings likely to resist swell.

The study (Cerema, 2018) provides a synthesis of investment costs as a function of the coastal length for shoreline management operations and for operations protecting against marine flooding. Table 1 shows the synthesis for coastal flood protection.

Tableau 1. Linear cost (low, medium, and high) for operations of protection against marine flooding

\begin{tabular}{|l|l|l|}
\hline Exposure to waves & Stakes to protect & Linear cost HT (M€/km) \\
\hline $\begin{array}{l}\text { Sheltered levee system (canals, } \\
\text { estuaries) }\end{array}$ & Mean natural and human stakes & $0,5<0,6<0,7$ \\
\cline { 2 - 3 } & High natural and human stakes & $0,7<0,85<1,0$ \\
\hline \multirow{2}{*}{$\begin{array}{l}\text { Levee system exposed to wave } \\
\text { (open waterfront) }\end{array}$} & Mean natural and human stakes & $1,0<1,5<2,0$ \\
\cline { 2 - 3 } & High natural and human stakes & $2,0<3,0<7,5$ \\
\hline
\end{tabular}




\section{Results obtained at the scale of natural features and civil engineering structures}

For the various intervention types affecting beaches, dunes, levees and other civil engineering works, the study (Cerema, 2018) offers a synthesis of the total costs as a function of the structure length. In addition, the surface, volume or mass costs relative to the various techniques are specified. If possible, the annual linear mean values for investment, maintenance, and management expenditures are also estimated by considering, for long durations, long structures.

The determining physical parameters can theoretically be of all kinds. In addition to the wave exposure evoked previously, the following parameters are also important:

- material quantities and equipment used (for example, for beach nourishment from the sea, the quantity of transported sand determines the dredge type, which induces strong disparities in the volume costs);

- material supply distance (earth or armourstone for levees, sand for beach or dune nourishment) and accessibility of the site;

- weather conditions, to which most of the strutures are very sensitive. In the case of dunes, if the rainfall intensity is sufficient and the wind orientation is favorable relative to the available foreshore sand stock, management and maintenance costs will be nearly zero. If one of these parameters is unfavorable, the preservation of the dune may require expensive interventions;

- construction modes: according to the mode of implementation, the same material will not present the same unit cost, nor the same life expectancy. For example, concrete blocks poured without iron bars will last much longer than reinforced concrete with a beam or plate shape.

The geotechnical and morphological constraints are also very important, but these complex parameters were only taken into account implicitly in the study through the technical choices of the project manager.

To illustrate the content of the study, two examples are shown here:

- levees with facing (exposed to swell), for which table 2 synthesizes the information relative to the construction, reconstruction or repair operations;

\begin{tabular}{|c|c|c|c|c|c|}
\hline Technique & $\begin{array}{l}\text { Number of } \\
\text { recorded } \\
\text { operations }\end{array}$ & $\begin{array}{l}\text { Linear cost } \\
\quad(€ / \mathrm{m})\end{array}$ & $\begin{array}{l}\text { Surface cost } \\
\quad\left(€ / \mathrm{m}^{2}\right)\end{array}$ & $\begin{array}{l}\text { Volume cost } \\
\qquad\left(€ / \mathrm{m}^{3}\right)\end{array}$ & $\begin{array}{l}\text { Mass cost } \\
\quad(€ / t)\end{array}$ \\
\hline $\begin{array}{l}\text { Earthwork and } \\
\text { armourstone }\end{array}$ & 2 & $\begin{array}{l}2000<2500<3100 \\
\text { (height between } 2 \text { and } 3 \mathrm{~m} \text { ) }\end{array}$ & $N / A$ & $\begin{array}{l}19<32<45 \\
\text { (earthwork) }\end{array}$ & $\begin{array}{c}17<21<24 \\
\text { (armourstone) }\end{array}$ \\
\hline $\begin{array}{c}\text { Armourstone and } \\
\text { concrete superstructure }\end{array}$ & 2 & $\begin{array}{l}5600<5800<6000 \\
\text { (height about } 8 \mathrm{~m} \text { ) }\end{array}$ & $N / A$ & $N / A$ & $\begin{array}{c}29<31<33 \\
\text { (armourstone) }\end{array}$ \\
\hline $\begin{array}{l}\text { Masonry and concrete } \\
\text { injection }\end{array}$ & 2 & $\begin{array}{c}1400<2300<3200 \\
\text { (height between } 2 \text { to } 3,5 \mathrm{~m} \text { ) }\end{array}$ & $\begin{array}{c}160<200<230 \\
\text { (masonry) }\end{array}$ & $\begin{array}{c}580 \\
\text { (concrete injection } \\
\text { and anchors) }\end{array}$ & $\mathrm{N} / \mathrm{A}$ \\
\hline Earthwork and gabions & 1 & 1500 (height about $2 \mathrm{~m}$ ) & $\mathrm{N} / \mathrm{A}$ & $\mathrm{N} / \mathrm{A}$ & $\mathrm{N} / \mathrm{A}$ \\
\hline $\begin{array}{l}\text { Reinforced concrete } \\
\text { and sheetpile }\end{array}$ & 1 & 14300 (height about 8m) & $N / A$ & $N / A$ & $\mathrm{~N} / \mathrm{A}$ \\
\hline
\end{tabular}

- timber groynes, for which detailed information are given in table 3. (Large volume cost differences emerge between simple piles and assemblies.)

\begin{tabular}{|l|l|}
\hline \multicolumn{2}{|c|}{ Tableau 3. Volume costs observed for groynes made of timber } \\
\hline Technique & Volume cost $(€ / \mathrm{m} 3)$ \\
\hline Assemblies of poling boards, sheetings and walings & 1700 \\
\hline Pile alignment & 660 \\
\hline
\end{tabular}




\section{Life expectancy and maintenance frequency}

Structure life expectancy and maintenance frequency is very important for the calculation of the global cost of a project. Based on a bibliographical study and on ground observations, values presented in table 4 are recommended for the structure types that are the most frequently used.

\begin{tabular}{|c|c|c|}
\hline \multicolumn{2}{|c|}{ Tableau 4. Mean values for life expectancy and maintenance frequency } \\
\hline Structure type & $\begin{array}{c}\text { Life expectancy (or duration between } \\
\text { two major repairs) }\end{array}$ & Maintenance frequency \\
\hline Levees covered with grass & 100 years & Annual \\
\hline Concrete or rock structures & 50 to 100 years 15 years \\
\hline Sheetpile structures & $\begin{array}{c}50 \text { years with cathodic protection } \\
100 \text { ans without cathodic protection }\end{array}$ & $\begin{array}{c}20 \text { years (replacement of sacrificial } \\
\text { anodes) }\end{array}$ \\
\hline Masonry structures & 100 years & 5 to 10 years \\
\hline Timber groynes & until 100 ans & $\begin{array}{c}\text { Annual (Repair of accidental tears or } \\
\text { replacement of deteriorated } \\
\text { elements) }\end{array}$ \\
\hline $\begin{array}{c}\text { Geotextile structures immersed or } \\
\text { protected with sand }\end{array}$ & 40 years & $\begin{array}{c}\text { Annual (Repair of accidental tears or } \\
\text { replacement of deteriorated } \\
\text { elements) }\end{array}$ \\
\hline $\begin{array}{c}\text { Geotextile structures exposed to } \\
\text { meteomarine conditions }\end{array}$ & 15 years & \multicolumn{2}{c}{} \\
\hline
\end{tabular}

\section{GENERIC LESSONS}

Based on unit costs observed during past projects and on the mean life expectancy and maintenance frequency, some general conclusions can be drawn. These conclusions are supported by the contents of the last part of the study, which presents a transverse analysis of the cost of techniques used on various types of civil engineering structures or natural features. The same techniques can be used in different conditions, and comparisons are instructive. (In the same way as in the previous sections of the handbook, comparisons can be established between different techniques used for the same purpose and under equivalent conditions.)

The study suggests strongly the importance of considering systematically alternative protection modes, instead of restricting the design process solely to traditional civil engineering techniques. In the medium term, at sites where strong stakes must be protected, the combination of several techniques (traditional or alternative) can be optimal to reach performance goals while optimizing global costs. If we consider very long timescales (duration equal or superior to 100 years), alternative techniques seem more adapted to respond to the challenges posed by sea level rise and increased wave power.

\section{Alternative protection modes to consider}

To protect against coastal hazards, several technical options are generally possible, with strong disparities regarding the environmental impacts but also regarding investment, maintenance, and management costs. In every case, it is advisable to study and compare the different options and the various possible combinations, in the littoral zone (integrating at the same time the foreshore and the land situated at the back of the sea front).

To prevent erosion, the alternative solutions to the traditional techniques consist in restoring the natural balance by:

- $\quad$ beach nourishment and dune reconstruction;

- timber groyne implantation;

- the implantation of geotextiles filled with sand that act as a breakwater;

- the implementation of beach drainage systems.

This set of measures can also contribute to maintain a sufficient sedimentary stock, thus assuring a better response of the coast exposed to the hydraulic forces (waves and storm surge) that cause flooding.

To prevent marine flooding, and as supplementary measures to techniques limiting erosion, better control of the flow may allow avoiding the construction or increase of levees. The precise evaluation of storage capacity in « buffer zones » at the back of the sea front, and good management of levees and hydraulic structures often allows defining less expensive protection strategies. 
From an economic point of view, every technical approach generates a particular expenditure rhythm. In most cases, it appears that:

- traditional techniques engender high investment costs, followed by management and maintenance costs that are irregular but also high;

- the use of natural materials (earth, sand, timber) involves, on the contrary, regular management and maintenance costs, but a lower global cost, even more so if these materials are available near the site that must be protected.

\section{The necessity at sites with high stakes to combine approaches}

There exist a wide variety of protection techniques, which can be combined, sometimes along the extent of the littoral zone. In particular, it should be noted that the height of a protection structure can be reduced when it is coupled with another structure placed seaward (breakwaters or groynes) or landward (setback levees).

One example of this strategy is the repair of the protection structures in Sangatte, illustrated in Figure 3. At this site, a civil engineering structure is associated with timber groynes. Groynes establish a first curtain that dissipates part of the wave energy and stabilizes the level of the foreshore, whereas the levee, covered with armourstone absorbs the remaining energy. This combination limits strongly wave reflection and nearshore erosion.
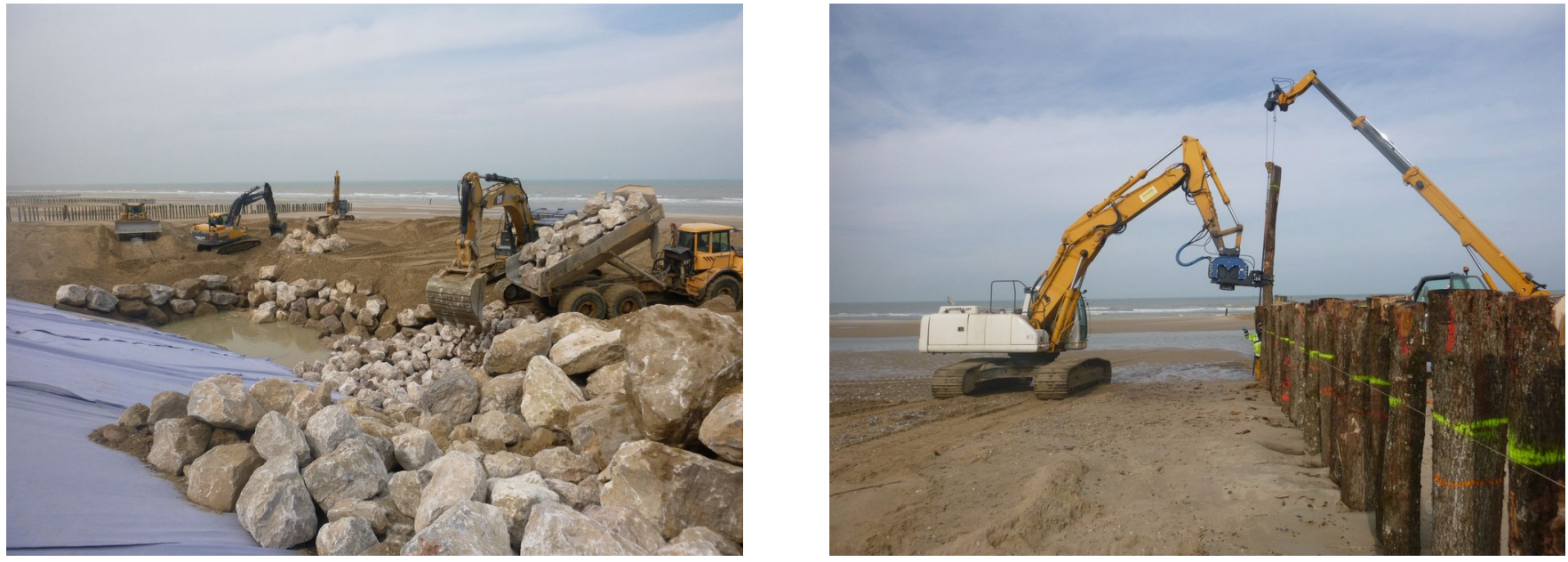

Figure 3. Construction site of Sangatte: implementation of armourstone on the levee (on the left) and of piles (on the right) - Source: DDTM 62

The strategies implemented recently in France show a wide range of solutions, as well as the necessity to take into account, from the beginning of the project, the structure management and maintenance costs.

To the extent possible, when developping the project strategy, it is strongly advised to consider the techniques used at nearby sites. Nevertheless currents, wave exposure, and sediment transport vary substantially depending on the site. Thus, additional investigations are necessary to ensure the relevance of a technique for a considered site.

\section{Climate change adaptation}

The study (Cerema, 2018) presents for every structure type the desired effects regarding the protection against littoral hazards and the way the effects of climate change, and more particularly sea level rise, could reduce the performance of these structures. From this point of view, a big disparity appears, with a much higher adaptation capacity of the natural features compared to civil engineering structures. Structures using natural materials and integrating natural processes generally present better resilience and lower global costs.

On long timescales, adaptation to climate change of levee systems requires good shoreline management (to increase sedimentary stocks) and adaptation of the flow management (using setback levees, retaining basins...). 


\section{CONCLUSIONS}

The cost study of coastal protections (Cerema, 2018) presents, for a wide range of protection scenarios, reliable data stemming from the observation of projects undertaken in France during the last fifteen years. Completed with the cooperation of the ministery of ecology and numerous local authorities, this handbook is designed to provide assistance in cost assessment at various stages of project development.

Beyond the data necessary for the calculation of the global project cost, the handbook gives a perspective on the multiple interventions that these protection systems require. Each of the components follows its own life cycle, and the project expenditures depend of these cycles. It also provides information about the behavior of the structures in a future impacted by the effects (sea level rise, changing wave conditions) of climate change. For all of these reasons, this study can also contribute to adjust national strategies regarding the protection against littoral hazards.

Based on projects observed during the same period and in the same country, all of the estimations benefit from a certain uniformity in the economic environment, which thus enables comparisons of the cost of the various techniques or their use in various environmental conditions. The generalization of the conclusions of this study to other countries must take into account differences in context that can exist, in particular concerning public policy strategies, and more concrete issues such as the availability of materials.

\section{REFERENCES}

Cerema, 2018. Coût des protections contre les aléas littoraux. Collection : connaissances. ISBN : 9782-37180-283-4

CGEDD, 2013. Mise en œuvre du Plan Submersions rapides sur les territoires touchés par la tempête Xynthia. Rapport $n^{\circ} 008933-01$

France Stratégie, 2013. L'évaluation socio-économique des investissements publics IGN, 2007. Les littoraux : entre nature et société, Publications de l'ENS, p. 228. 